\title{
Research on provincial forestry investment efficiency in China
}

\author{
Shihong Zeng ${ }^{1,2,3, *}$, Runtong Liu ${ }^{1,2}$, Ya Zhou ${ }^{1,2}$ and Xiaobo He ${ }^{1,2, *}$
}

\begin{abstract}
Forestry is the largest carrier of the green economy. Its strong ecological and economic effect makes it the object of green investment. To explore whether Chinese forestry investment is effectively utilized, we measured the input-output efficiency of forestry investment in 31 provinces in China through the super-slack-based measure model and the Malmquist index in the data envelopment analysis model. Based on this, we further analyze the redundant (insufficient) situation of input (output) in inefficient regions and changes in the efficiency of China's forestry investment. The results show that the comprehensive efficiency of forestry investment in most provinces of China is low, among which the developed provinces are limited by input factors, while the less developed provinces are affected by low-scale efficiency. Second, the environmental benefit of forestry investment in the sample area is not obvious, and the output of forest carbon sequestration is low. Third, the efficiency of forestry investment in most provinces of China is improving, but the application technology of forestry investment has become the main factor hindering the improvement of forestry investment efficiency.
\end{abstract}

JEL classification numbers: E22, Q23, Q54

Keywords: Forestry, investment efficiency, China

\footnotetext{
${ }^{1}$ Applied Economics Department,College of Economics \& Management, Beijing University of Technology, Beijing 100124, China.*Corresponding authors e-mail:zengshihong@bjut.edu.cn (S. Zeng); lrt743174707@163.com(R. Liu); zhouya0929jingguan@163.com (Y.Zhou);

${ }^{2}$ Finance and Economics Development Research Center,College of Economics \& Management, Beijing University of Technology, Beijing 100124, China. e-mail:hexiaobo@bjut.edu.cn (X. He)

${ }^{3}$ Beijing Modern Manufacturing Development Research Base of Beijing Philosophy and Social Sciences, Beijing University of Technology, Beijing 100124, China.
}

Article Info: Received: June 3, 2021. Revised: June 20, 2021.

Published online: June 25, 2021. 


\section{Introduction}

At present, global climate change has become the focus of attention of all countries in the world. Vigorously developing a green economy and increasing green investment are considered by many scholars to be one of the most effective ways to mitigate climate change and achieve ecological balance (Sobrinho et al., 2020; Dmuchowski et al., 2021; Baniya et al., 2021). Many scholars have conducted research on green investment. They found that green investment can not only reduce the emission of greenhouse gases and air pollutants (Khovanskaia and Ivanyi ,2007) but also create new employment opportunities (Banacloche et al., 2020), effectively reduce the environmental burden in the process of economic growth (Ottelin et al., 2018), and beautify the city (Mell et al., 2016).

Generally, green investment will flow to two channels in terms of reducing air pollution and greenhouse gas emissions: one is to control air pollution and greenhouse gas emissions from the source, and the other is to control the air pollution and greenhouse gases that have been generated. In the first aspect, energy consumption is one of the main causes of air pollution and greenhouse gas emissions (Moriarty and Honnery, 2019). Hence, many studies have been carried out on green energy investment (Bostian et al., 2016; Lundgren, et al., 2018; $\mathrm{Ng}$ and Zheng, 2018). However, some scholars have considered environmental governance because the current environment has been under great pressure, and reducing the environmental load is urgent. Therefore, some scholars have begun to consider the second aspect. That is, how to control the air pollution and greenhouse gases that have been generated through environmental governance. Some scholars found that forestry investment may be an effective means to reduce air pollution and greenhouse gas emissions, so they began to study forestry and achieved certain research results (e.g., Kangas et al., 2011; Alix-Garcia et al., 2015; Li et al., 2017; Lin et al., 2019; Nery et al., 2019; Rode et al., 2019; Zhang et al., 2019). For example, Alix-Garcia et al. (2015) used several new datasets to assess the impact of ecological compensation schemes on the environment and wealth and found that forest maintenance compensation payments reduce land cover loss and have a small positive effect on poverty alleviation. Nery et al. (2019) studied the spatial pattern of forestry investment in Western Australia and assessed the determinants of land change in plantations. They found that the factors influencing the changes in plantations include soil depth, proximity to urban centers, and use of surrounding soil. The study shows that there are many factors that affect the distribution of forestry investment and that forestry investment can indeed bring significant environmental and social benefits in many countries.

According to data released by the National Bureau of Statistics of China (http://www.stats.gov.cn/), China's forestry investment reached 474.3 billion yuan in 2018, 12.3 times the 2004 forestry investment (38.3 billion yuan), with an average annual compound growth rate of $19.69 \%$. At the same time, China contributed $25 \%$ of the world's net increase in leaf area, of which $42 \%$ came from 
forest resources (Chen et al., 2019). China's planted forest area accounts for approximately $27 \%$ of the world's planted forest area, which makes China's forest resources store a large amount of carbon (Schulze et al., 2000) and contributes significantly to the world's carbon storage (Zhang et al., 2020). Therefore, these forest resources in China play a vital role in mitigating climate warming, especially in reducing the concentration of carbon dioxide in the atmosphere (Fang et al., 2014; Griscom et al., 2017).

Therefore, is such a large-scale forestry investment worthwhile compared with the benefits generated? In other words, we are interested in assessing whether the efficiency of forestry green investment is efficient. Investment efficiency refers to the input-output problem of the forestry industry at the macro level. However, under the background of air pollution and greenhouse gas emissions, what role does the function of the forest absorbing carbon dioxide and sulfur dioxide play in the evaluation of forestry green investment projects at the micro level? The detailed study of forestry investment in this paper answers these questions and is of practical significance and value.

Total factor productivity (TFP) is an indicator of economic efficiency (Lin and Ge, 2019; Xiao et al., 2021). The essence of TFP reflects the utilization efficiency of all types of resources (Cai et al., 2018). Therefore, we believe that TFP is a good indicator of the efficiency of China's forestry investment. In fact, many scholars have already applied TFP to green investment (Allevi et al., 2019), forestry resources ( $\mathrm{Li}$ et al., 2017), environmental efficiency (Wen et al., 2018), and renewable energy (Sohag et al., 2021). Their research methods can provide us with a certain theoretical basis. In addition, we are also concerned that some scholars have carried out research on China's forestry. Li et al. (2017) studied the utilization efficiency of forestry resources in China and found that technical factors are the key factors restricting the utilization efficiency of forestry resources. Zhang et al. (2019) analyzed the investment return rate of China's plantation forests and found that the return rates of different regions and different tree species were different. Lin and Ge (2019) studied the output relationship of China's forestry sector and found that environmental factors are the main factors affecting forestry output. Wu and Zhang (2020) found that there is a nonlinear relationship between Internet technology upgrades and forest TFP. Their research on China's forestry also provides a theoretical basis for our research.

In summary, green investment has attracted increasing attention, but most scholars are more inclined to choose energy as the research object, and there is very little research on forestry investment. This may be due to difficulties in data collection. In recent years, a few scholars have begun to pay attention to the important role of forestry in mitigating global climate change and have carried out research on forestry investment. Our research aims to explore the true level of China's forestry investment efficiency from the perspective of input and output through the total factor productivity index and to analyze the reasons for the formation of forestry investment efficiency and its temporal and spatial characteristics.

This research differs from previous scholars' research on China's forestry 
investment in the following aspects and may contribute as follows: (1) Our research not only considers economic performance (forestry output value) but also considers environmental performance, which includes forest carbon sinks (the ability of forests to reduce carbon emissions) and sulfur dioxide emissions (the ability of forests to purify air). (2) Our research attempts to use the Super-Slack-Based Measure (Super-SBM) model to statically measure the efficiency of forestry investment in various provinces and cities in China, compare it among different regions, and use slack variables to interpret the reasons for the difference in efficiency. (3) We will further adopt the Malmquist index in the Data Envelopment Analysis (DEA-Malmquist) model to dynamically measure the changes in China's forestry investment efficiency.

The rest of this article is arranged as follows: The second part will introduce the model used in this article. The third part will conduct an empirical study on the efficiency of China's forestry investment. Finally, in the fourth part, we put forward our conclusions and suggestions.

\section{Methods and Data}

\subsection{Model}

Our paper includes three models: the forest biomass conversion factor model, the Super-SBM model and the DEA-Malmquist model. We use the forest biomass conversion factor model to measure the forest carbon sinks at the provincial level in China, and we use the Super-SBM model and the DEA-Malmquist model to measure the static production efficiency and dynamic production efficiency of forest investment at the provincial level in China, respectively.

\subsubsection{Forest biomass conversion factor model}

Forest carbon sinks mean that forest plants absorb carbon dioxide in the atmosphere and fix it in vegetation or soil, thereby reducing the concentration of gas in the atmosphere. Forest carbon sinks are one of the most important carbon dioxide sequestration methods and can effectively alleviate global warming (Qiu et al., 2020; Lin and Ge, 2019). Therefore, we will calculate the forest carbon sink and use it as one of the output indicators of forestry investment.

Current research shows that there is uncertainty in the measurement of forest carbon sinks, and no one method is absolute good. Thus, relatively appropriate measurement methods can be selected only according to the forest characteristics. Generally, the methods commonly used to study the carbon sequestration of forests include the biomass method, volumetric method and atmospheric flow method (e.g., Winjum et al., 1998; Wang et al., 2001; Chhabra, 2002; Jalkanen et al., 2005; Fang et al., 2007; Somogyi et al., 2007; Deng et al., 2014). Considering the limitation of forestry data at the provincial level in China, this paper uses the forest biomass conversion factor model to calculate forest carbon sinks. The carbon sink value measured in this paper is used only for economic measurement and does not need to reach the accuracy of natural science. Therefore, to reduce 
the computational complexity, this method is more appropriate.

The calculation process of the forest biomass conversion factor model is as follows: first, forest growth volume is converted into growth volume density, and then the growth volume density and biomass expansion factor are used to calculate the aboveground biomass; finally, the carbon sink is calculated based on the conversion coefficient of carbon fixation.

This paper defines the forest carbon sequestration equation (Equation 1) as follows:

The forest carbon sequestration $=$ Forest biomass carbon sequestration

The specific calculation equation of carbon sequestration using the forest biomass conversion factor method is as follows (Fang et al., 2007):

$\operatorname{Carb}_{i j}=A_{i j} \times B E F_{i j} \times$ Density $_{i j} \times \gamma_{i j}$

where, Carbrefers to the amount of carbon sequestration in a forest. $A, B E F$, Density and $\gamma$ represent the total standing forest stock, biomass expansion factor, bulk density and carbon content rate, respectively. $i$ and $j$ refer to province $i$ and year $j$, respectively. The coefficients in different regions and periods are uncertain. Combined with the current situation of China's forests and the requirements of the Intergovernmental Panel on Climate Change (IPCC) 2000, this paper uniformly adopted a biomass expansion factor of 1.90 , a bulk density of 0.50 and a carbon content rate of 0.5 .

\subsubsection{Super-SBM model}

The data envelopment analysis (DEA) model is an analytical method that uses linear programming to evaluate the relative nonparametric technical efficiency of decision objects with multi-index outputs and multi-index inputs. If the improvement of decision-making units (DMUs) is that all inputs (outputs) are reduced (increased) in the same proportion, this kind of DEA model is called a radial model. Otherwise, it is a nonradial model.

The slack-based measure (SBM) model adopted in this paper is a nonradial model with the longest distance to the front. The SBM model is based on the traditional DEA model proposed by Tone (2001). The SBM model mainly solves the radial problem in the traditional DEA model. When there is a gap between the DMU and the strongly effective target value, the DMU is invalid. What makes the SBM model superior to the radial model is that it considers both the geometric ratio improvement of the input (output) and the improvements of the slack variables. In addition, to solve the problem of multiple DMU efficiency values being 1 in DEA model analysis, the Super-SBM model is adopted in this paper. The Super-SBM model was proposed by Tone (2002), who combined superefficiency with the SBM model. Its advantage is that effective DMU groups can be compared, and the efficiency value can exceed 1 . The nonradial Super-SBM model used in this paper is shown in Equation 3: 


$$
\begin{gathered}
\min \rho_{S E}=\frac{\frac{1}{m} \sum_{i=1}^{m} \frac{\bar{x}_{i}}{x_{i k}}}{\frac{1}{S} \sum_{r=1}^{s} \frac{\bar{y}_{r}}{y_{r k}}} \\
\text { s.t. }\left\{\begin{array}{c}
\bar{x}_{i} \geq \sum_{j=1, j \neq k}^{n} x_{i j} \lambda_{j} \\
\bar{y}_{r} \leq \sum_{j=1 ; j \neq k}^{n} y_{r j} \lambda_{j} \\
\bar{x}_{i} \geq x_{i k} \\
\bar{y}_{r} \leq y_{r k} \lambda \\
s^{-}, s^{+}, \bar{y} \geq 0 \\
n=1,2, \ldots, m ; r=1,2, \ldots, q ; j=1,2, \ldots, n(j \neq k) \\
\sum_{j=1 ; j \neq k}^{n} \lambda_{j}=1
\end{array}\right.
\end{gathered}
$$

The production set calculated by other DMUs is:

$$
\left\{(x, y) \mid x \geq \sum_{j=1, j \neq k}^{n} x_{i j} \lambda_{j}, y \leq \sum_{j=1 ; j \neq k}^{n} y_{r j} \lambda_{j}\right\}
$$

where $\rho_{S E}$ represents the efficiency value of the evaluated DMU in Equation (3). At the same time, because this model is also nonoriented, the measurement of $\rho_{S E}$ is considered from both input and output.

\subsubsection{DEA-Malmquist model}

Because the TFP calculated by the Super-SBM model is static, in other words, the efficiency calculated by it is only the efficiency value of the year at that time. Therefore, the Super-SBM model cannot dynamically measure the changes in TFP from the time dimension. Therefore, we will use the DEA-Malmquist model to dynamically analyze forestry investment efficiency. The Malmquist index was originally proposed by Swedish economist Malmquist (1953) and used for two sets of consumption indexes in different periods. Caves et al. (1982) improved it to a Malmquist index that can measure productivity. Based on the DEA method, Färe (1994) changes the Malmquist index from a theoretical index to an empirical index and decomposes it into technical efficiency and technological progress rate. Ray and Desli (1997) made further amendments to this so that the technical efficiency of the Malmquist index can be further decomposed into pure technical efficiency and scale efficiency under scale changes. The specific calculation formula is shown in Equation 4:

$$
M_{i}=\left(X_{t}, Y_{t}, X_{t+1}, Y_{t+1}\right)=\left(\frac{D_{t+1}\left(X_{t}, Y_{t}\right)}{D_{t+1}\left(X_{t+1}, Y_{t+1}\right)} \times \frac{D_{t}\left(X_{t}, Y_{t}\right)}{D_{t}\left(X_{t+1}, Y_{t+1}\right)}\right)^{\frac{1}{2}}
$$




$$
\begin{gathered}
=\frac{D_{t}\left(X_{t}, Y_{t}\right)}{D_{t+1}\left(X_{t+1}, Y_{t+1}\right)} \times\left(\frac{D_{t+1}\left(X_{t+1}, Y_{t+1}\right)}{D_{t}\left(X_{t+1}, Y_{t+1}\right)} \times \frac{D_{t+1}\left(X_{t}, Y_{t}\right)}{D_{t}\left(X_{t}, Y_{t}\right)}\right)^{\frac{1}{2}} \\
=T E C_{t+1} \times T P_{t+1} \\
=P E_{t+1} \times S E_{t+1} \times T P_{t+1}
\end{gathered}
$$

In Equation 4, the distance functions $D_{t}\left(X_{t}, Y_{t}\right)$ and $D_{t+1}\left(X_{t+1}, Y_{t+1}\right)$ represent the distance between the observation point and the frontal surface in periods $t$ and $t+1$, and $D_{t}\left(X_{t+1}, Y_{t+1}\right)$ and $D_{t+1}\left(X_{t}, Y_{t}\right)$ represent the maximum value of the possible reduction of $\left(X_{t+1}, Y_{t+1}\right)$ and $\left(X_{t}, Y_{t}\right)$ input under the feasible conditions under the technical conditions of periods $t$ and $t+1$. $M$ represents the Malmquist index. When $M>1$, the efficiency is improved; when $M=1$, the efficiency is unchanged; and when $M<1$, the efficiency is reduced.

It can be seen from the above that the Malmquist index is further decomposed into technical efficiency change (TEC) and technological progress (TP). At the same time, the TEC can be decomposed into pure technical efficiency (PTE) and scale efficiency (SE). Among them, TEC is the relative efficiency change, which represents the degree of catch-up from the DMU to the production frontier from period $t$ to period $t+1$. TP is the change in production technology in two adjacent periods, which represents the movement of the production frontier. PTE and SE are also changes in relative efficiency, which refer to the changes in the ability to obtain the maximum output under a given input and the changes in the distance from the optimal investment scale from period $t$ to period $t+1$, respectively.

\subsection{Data}

\subsubsection{Input and output variables}

Before we use the Super-SBM model and the DEA-Malmquist model to evaluate the efficiency of China's forestry investment, we need to select appropriate input variables and output variables. We first determine that the production endowments are mainly land, capital and labor according to classical economic theory. We map the theoretical production relationship to forestry production, and then the three production factors become the forestry investment, number of forestry system employees, and forestry land area. This input variable setting method is also consistent with the choices made by researchers such as Li et al. (2017), Lin and Ge (2019), and Wu and Zhang (2020) in related research.

Our output variables consider two aspects: one is the economic benefits brought about by forestry investment, and the other is the environmental benefits brought about by forestry investment. The economic benefit is measured by the value of forestry output, which is the same as the choice of most researchers (e.g., Li et al., 2017; Lin and Ge, 2019; Wu and Zhang, 2020). However, in terms of environmental benefits, we also consider two aspects: one is the benefit of carbon emission reduction, and the other is the benefit of environmental purification. We 
use forest carbon sinks to measure the benefits of carbon emission reduction. Environmental purification benefits are limited by the availability of data and will be measured by the reduction of sulfur dioxide emissions. China is the country with the largest sulfur dioxide emissions in the world, which has severely affected China's environment (Zeng et al., 2018). The forest can absorb sulfur dioxide to a certain extent, thereby purifying the air (Parsa et al., 2019).

\subsubsection{Data Sources}

We study forestry investment efficiency using provincial panel data from China (excluding Hong Kong, Taiwan and Macao) from 2004 to 2018. The sources of datasets are mainly as follows: China Statistical Yearbook, China Forestry Statistical Yearbook, and National Bureau of Statistics of China. Among them, the amount of forestry investment, forestry area, forestry output value, and sulfur dioxide emissions data come from the National Bureau of Statistics of China. Data on forestry practitioners come from the China Forestry Statistical Yearbook. The forest carbon sink is calculated by Equation 2 from the total standing forest stock from the China Statistical Yearbook.

China's forest resource inventory is conducted every five years. The sample period in this paper was from 2004 to 2018, during which three national forest inventory periods were conducted: from 2004 to 2008, from 2009 to 2013, and from 2014 to 2018. Furthermore, the national statistical report shows that the annual data of forest resources are all the same during the 5-year inventory period, which is not consistent with reality. Therefore, this paper assumes that the forest between the two inventory periods grows at a uniform rate and supplements the data according to this assumption. Sulfur dioxide emission reductions are measured by the reduction in sulfur dioxide emissions relative to the previous year.

\subsubsection{Descriptive statistics}

To understand the distribution of input and output, descriptive statistical analysis of the data was carried out. The results are shown in Table 1, which shows the descriptive statistical results of the input variables and output variables.

Table 1 : Summary statistics of the input variables and output variables

\begin{tabular}{|c|c|c|c|c|c|c|}
\hline variable & unit & obs & Mean & Std. & Min & Max \\
\hline I_fp & thousand people & 465 & 40.95 & 56.39 & 0.16 & 370.07 \\
\hline I_fa & thousand hectares & 465 & 184.53 & 166.87 & 0.71 & 861.90 \\
\hline I_fi & billion yuan & 465 & 8.09 & 13.12 & 0.03 & 108.61 \\
\hline O_fcs & million tons & 465 & 263.06 & 308.70 & 1.43 & 1100.96 \\
\hline O_fov & billion yuan & 465 & 10.17 & 9.23 & 0.17 & 39.69 \\
\hline O_SO2 & million tons & 465 & 0.41 & 0.12 & 0.00 & 1.10 \\
\hline
\end{tabular}

In Table 1, I_fp represents the total number of employees in the forestry system, 
I_fa represents the afforestation area, I_fi represents the forest investments, O_fcs represents the forest carbon sinks, O_fov represents the forestry output value, and O_SO2 represents the sulfur dioxide emission reduction. As seen from Table 1, there is a clear gap between the maximum and minimum values of the input variables and output variables. This means that during the sample period, the forestry system inputs and outputs of different provinces in China vary greatly.

Fig. 1 shows the trend of forestry investment in 31 provinces of China from 2004 to 2018. In Fig. 1, we find that forestry investment in most provinces in China is increasing year by year, and the increase is rapid. This shows that China has paid increasing attention to forest resources in recent years. We have also found that in recent years, forestry investment in some provinces, such as Shanxi, Liaoning, Jiangsu, Fujian, Jiangxi, and Henan, has begun to show a downward trend. At the same time, we found that the area with the largest average forestry investment is Guangxi, with a staggering RMB 53 billion. This may be related to its own regional characteristics and industrial positioning. The area with the smallest average forestry investment is Hainan, with only 0.86 billion yuan. Followed by Tianjin, approximately 0.96 billion yuan. In addition, we found that the fluctuation of forestry investment in China's more economically developed provinces, such as Chongqing, Shanghai, and Tianjin, are relatively small and stable at a relatively low level. In those economically developed provinces, there may be two reasons for the relatively low investment in forestry: one is restricted by natural endowments such as land area; the other is that the development of service industries and manufacturing takes place at the core of these fields, and capital and labor are more inclined to flow into the production activities of these leading industries.

\section{Results}

The Super-SBM model can calculate the total factor productivity of forestry investment in each year. Therefore, it can be used to measure the static efficiency of forestry investment in different provinces in China. The DEA-Malmquist model is a dynamic measurement that can analyze the changes in China's forestry investment efficiency. This article measures the efficiency level of China's forestry investment from both static and dynamic aspects.

\subsection{Forestry investment efficiency of Super-SBM model}

Table 2 shows the overview of China's forestry investment efficiency values from 2004 to 2018 and calculated by the Super-SBM model. In Table 2, C_ET represents the result of calculating the Super-SBM model based on constant returns to scale (Super-SBM-CRS), which is the value of technical efficiency, including scale efficiency. V_ET represents the result of calculating the Super-SBM model based on variable returns to scale (Super-SBM-VRS), which is a pure technical efficiency value excluding scale efficiency. Therefore, we can use the relationship between C_ET and V_ET (as shown in Equation 5) to further 
calculate the scale efficiency value (we use ScaleE to represent). Among them, the technical efficiency value, pure technical efficiency value, and scale efficiency value here are different from those in the DEA-Malmquist model, and they are static.
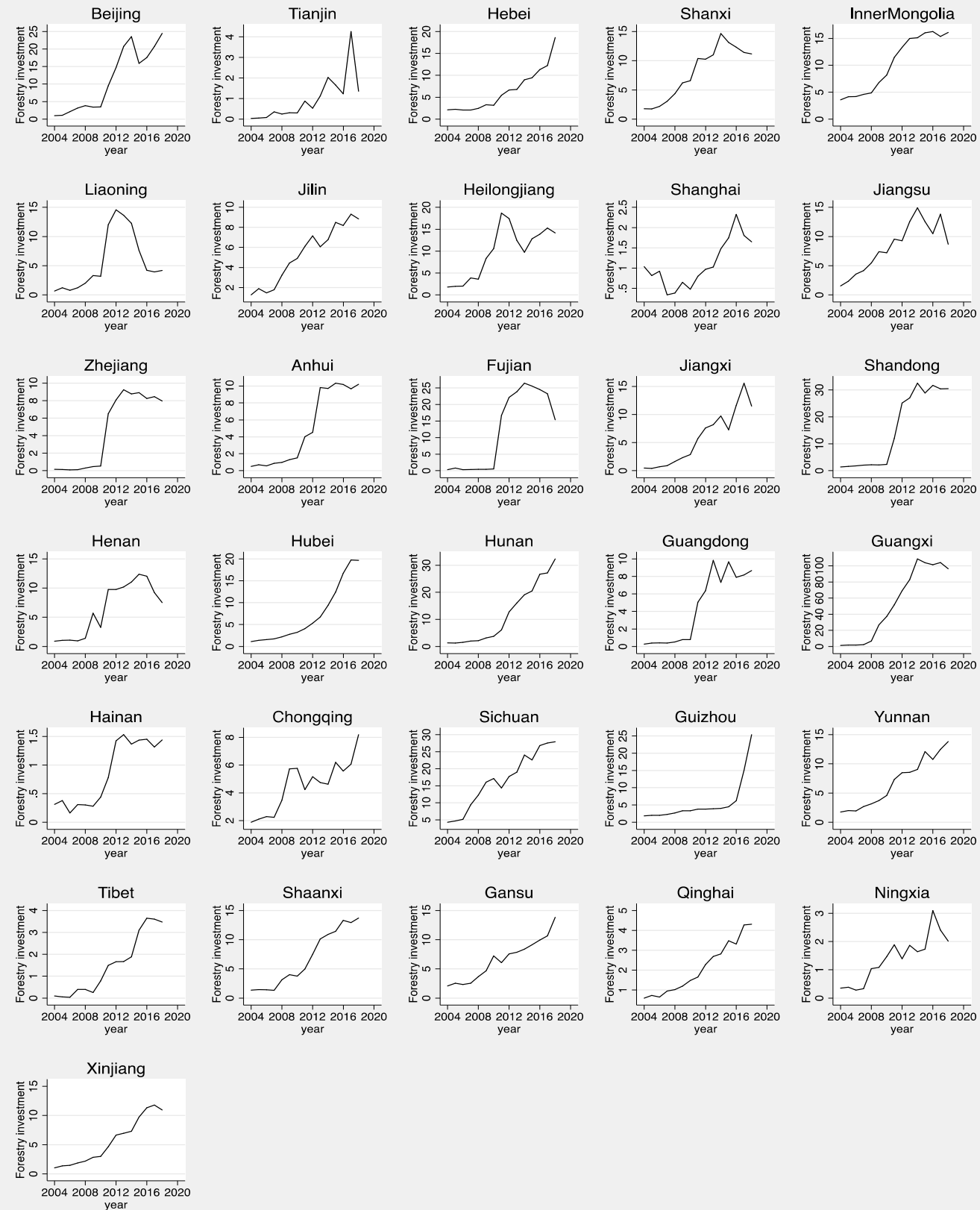

Unit: RMB 1 billion

Figure 1: Trends in forestry investment in various provinces during 2004-2018 
Technical efficiency represents the comprehensive efficiency of forestry investment and includes comprehensive measurement indicators of various capabilities, such as resource allocation capabilities and resource utilization efficiency. The pure technical efficiency value reflects the ability to obtain maximum output under a given input, and scale efficiency reflects whether to operate under the most suitable investment scale. In addition, equation 5 shows:

ScaleE $=\frac{\mathrm{C}_{-} \mathrm{TE}}{V_{-} P T E}$

From Table 2, we find that only Tianjin, Shanghai, Zhejiang, Hainan, and Tibet have comprehensive forestry efficiency values (i.e., C_TE, including pure technical efficiency and scale efficiency) that are greater than 1 . This shows that they are at the forefront of production, have a reasonable input-output ratio and are the most efficient. They are also the objects that other provinces should imitate and learn from. The comprehensive forestry efficiency values of the remaining provinces are all less than 1, indicating that the ratio between input and output in these provinces is not balanced, and forestry investment is in a low-efficiency state. Overall, the current comprehensive forestry investment efficiency of China's provinces is not ideal, and the comprehensive forestry investment efficiency of most provinces is below 0.5 , showing a long tail situation. In addition, the pure technical efficiency and scale efficiency of China's forestry investment also show a similar situation. Figure 2 more intuitively reflects the changes in the efficiency of forestry investment in various provinces in China over the years.

Table 2: China's forestry investment efficiency in 2004, 2011, and 2018

\begin{tabular}{|l|l|l|l|l|l|l|l|l|l|l|l|l|}
\hline \multirow{2}{*}{ Province } & \multicolumn{9}{|c}{ C_TE } & \multicolumn{1}{|c|}{ V_PTE } & \multicolumn{4}{c|}{ ScaleE } \\
\cline { 2 - 12 } & mean & std. & min & max & mean & std. & min & max & mean & std. & min & max \\
\hline Beijing & 0.05 & 0.04 & 0.01 & 0.16 & 0.19 & 0.33 & 0.02 & 1.01 & 0.79 & 0.33 & 0.01 & 1.00 \\
\hline Tianjin & 1.22 & 0.08 & 1.09 & 1.35 & 1.69 & 0.65 & 1.10 & 3.38 & 0.78 & 0.17 & 0.40 & 0.98 \\
\hline Hebei & 0.04 & 0.02 & 0.00 & 0.07 & 0.45 & 0.44 & 0.03 & 1.05 & 0.21 & 0.21 & 0.02 & 0.83 \\
\hline Shanxi & 0.03 & 0.02 & 0.00 & 0.06 & 0.26 & 0.32 & 0.01 & 1.01 & 0.27 & 0.23 & 0.04 & 0.74 \\
\hline Inner Mongolia & 0.07 & 0.04 & 0.01 & 0.15 & 0.40 & 0.41 & 0.02 & 1.13 & 0.29 & 0.16 & 0.05 & 0.60 \\
\hline Liaoning & 0.11 & 0.09 & 0.00 & 0.29 & 0.47 & 0.40 & 0.00 & 1.11 & 0.32 & 0.17 & 0.08 & 0.70 \\
\hline Jilin & 0.27 & 0.33 & 0.10 & 1.15 & 0.38 & 0.31 & 0.13 & 1.16 & 0.64 & 0.21 & 0.33 & 1.00 \\
\hline Heilongjiang & 0.12 & 0.07 & 0.04 & 0.24 & 0.92 & 0.33 & 0.31 & 1.24 & 0.14 & 0.06 & 0.04 & 0.20 \\
\hline Shanghai & 1.40 & 0.08 & 1.28 & 1.55 & 2.47 & 1.01 & 1.35 & 4.59 & 0.66 & 0.24 & 0.32 & 1.00 \\
\hline Jiangsu & 0.09 & 0.08 & 0.01 & 0.23 & 0.61 & 0.48 & 0.03 & 1.11 & 0.24 & 0.20 & 0.02 & 0.80 \\
\hline Zhejiang & 1.01 & 0.40 & 0.22 & 1.75 & 1.14 & 0.29 & 0.38 & 1.78 & 0.87 & 0.22 & 0.35 & 1.00 \\
\hline Anhui & 0.50 & 0.46 & 0.07 & 1.44 & 0.78 & 0.42 & 0.26 & 1.47 & 0.60 & 0.33 & 0.15 & 1.00 \\
\hline Fujian & 0.63 & 0.42 & 0.11 & 1.19 & 1.12 & 0.06 & 1.05 & 1.23 & 0.55 & 0.35 & 0.10 & 1.00 \\
\hline Jiangxi & 0.14 & 0.04 & 0.08 & 0.22 & 0.57 & 0.27 & 0.23 & 1.06 & 0.28 & 0.12 & 0.11 & 0.60 \\
\hline
\end{tabular}




\begin{tabular}{|l|l|l|l|l|l|l|l|l|l|l|l|l|}
\hline \multirow{2}{*}{ Province } & \multicolumn{4}{|c|}{ C_TE } & \multicolumn{5}{c|}{ V_PTE } & \multicolumn{4}{c|}{ ScaleE } \\
\cline { 2 - 7 } & mean & std. & min & max & mean & std. & min & max & mean & std. & min & max \\
\hline Shandong & 0.04 & 0.02 & 0.01 & 0.08 & 0.61 & 0.46 & 0.03 & 1.17 & 0.13 & 0.16 & 0.02 & 0.67 \\
\hline Henan & 0.07 & 0.05 & 0.00 & 0.15 & 0.55 & 0.43 & 0.00 & 1.09 & 0.20 & 0.15 & 0.04 & 0.53 \\
\hline Hubei & 0.09 & 0.04 & 0.02 & 0.14 & 0.22 & 0.15 & 0.04 & 0.46 & 0.50 & 0.20 & 0.30 & 0.87 \\
\hline Hunan & 0.08 & 0.03 & 0.02 & 0.15 & 0.72 & 0.35 & 0.27 & 1.04 & 0.14 & 0.08 & 0.02 & 0.30 \\
\hline Guangdong & 0.59 & 0.43 & 0.15 & 1.44 & 1.02 & 0.30 & 0.30 & 1.53 & 0.59 & 0.34 & 0.13 & 0.99 \\
\hline Guangxi & 0.07 & 0.02 & 0.03 & 0.09 & 0.59 & 0.41 & 0.11 & 1.11 & 0.18 & 0.12 & 0.06 & 0.42 \\
\hline Hainan & 1.30 & 0.16 & 1.10 & 1.56 & 1.33 & 0.17 & 1.11 & 1.63 & 0.98 & 0.02 & 0.93 & 1.00 \\
\hline Chongqing & 0.19 & 0.25 & 0.02 & 1.02 & 0.37 & 0.32 & 0.03 & 1.07 & 0.51 & 0.23 & 0.16 & 0.97 \\
\hline Sichuan & 0.10 & 0.04 & 0.03 & 0.15 & 0.82 & 0.32 & 0.36 & 1.14 & 0.12 & 0.05 & 0.06 & 0.26 \\
\hline Guizhou & 0.12 & 0.08 & 0.02 & 0.27 & 0.50 & 0.41 & 0.03 & 1.04 & 0.39 & 0.25 & 0.05 & 0.88 \\
\hline Yunnan & 0.16 & 0.09 & 0.05 & 0.33 & 1.29 & 0.05 & 1.19 & 1.38 & 0.12 & 0.06 & 0.04 & 0.24 \\
\hline Tibet & 1.77 & 0.90 & 1.42 & 4.97 & 1.83 & 1.14 & 1.42 & 5.90 & 0.99 & 0.04 & 0.84 & 1.00 \\
\hline Shaanxi & 0.08 & 0.04 & 0.01 & 0.13 & 0.21 & 0.16 & 0.03 & 0.53 & 0.49 & 0.22 & 0.18 & 0.97 \\
\hline Gansu & 0.05 & 0.03 & 0.01 & 0.08 & 0.08 & 0.05 & 0.01 & 0.19 & 0.71 & 0.24 & 0.25 & 0.98 \\
\hline Qinghai & 0.04 & 0.02 & 0.01 & 0.09 & 0.04 & 0.02 & 0.01 & 0.09 & 0.94 & 0.13 & 0.62 & 1.00 \\
\hline Ningxia & 0.01 & 0.01 & 0.00 & 0.05 & 0.10 & 0.26 & 0.00 & 1.00 & 0.72 & 0.33 & 0.03 & 1.00 \\
\hline Xinjiang & 0.10 & 0.05 & 0.02 & 0.16 & 0.19 & 0.24 & 0.03 & 1.00 & 0.76 & 0.24 & 0.13 & 0.99 \\
\hline
\end{tabular}

Note: C_TE, V_PTE and ScaleE represent the results calculated by the super-SBM-CRS model, the super-SBM-VRS model and equation 5, respectively.

Figure 2 shows that the efficiency of comprehensive forestry investment in most provinces in China is constantly improving. However, the comprehensive forestry investment efficiency of Jilin, Zhejiang, Anhui, Fujian, Guangdong, and Hainan has fluctuated greatly, and the fluctuation range is relatively obvious. This shows that the relationship between forestry production input and output in these provinces is in an unstable state.

In addition, we found that the scale efficiency values of Beijing, Tianjin, Shanghai, Zhejiang, Guangdong, Hainan, Tibet, and Qinghai remain at approximately 1. Among these provinces, only Beijing, Guangdong and Qinghai are the provinces with low comprehensive forestry investment efficiency, which means that pure technical efficiency is a key factor directly affecting their low comprehensive forestry investment efficiency. For example, we found that after 2006, the value of pure technical efficiency in Beijing dropped sharply, the scale efficiency was basically stable, and there may be an unreasonable input-output structure. Beijing is one of the cities with the highest level of economic development and urbanization in China. As we all know, its land resources are extremely limited, which greatly restricts the development of its forestry investment activities so that no amount of forestry investment can produce good benefits. In contrast, we found 
that in the provinces of Fujian, Shandong, Guangxi, Sichuan and Yunnan, pure technical efficiency was always maintained at approximately 1 . Therefore, the inefficiency of scale efficiency is a key factor directly leading to the inefficiency of comprehensive forestry investment in these provinces. This shows that the input-output structure of the forestry industry in these provinces is reasonable, but the scale needs to be increased.
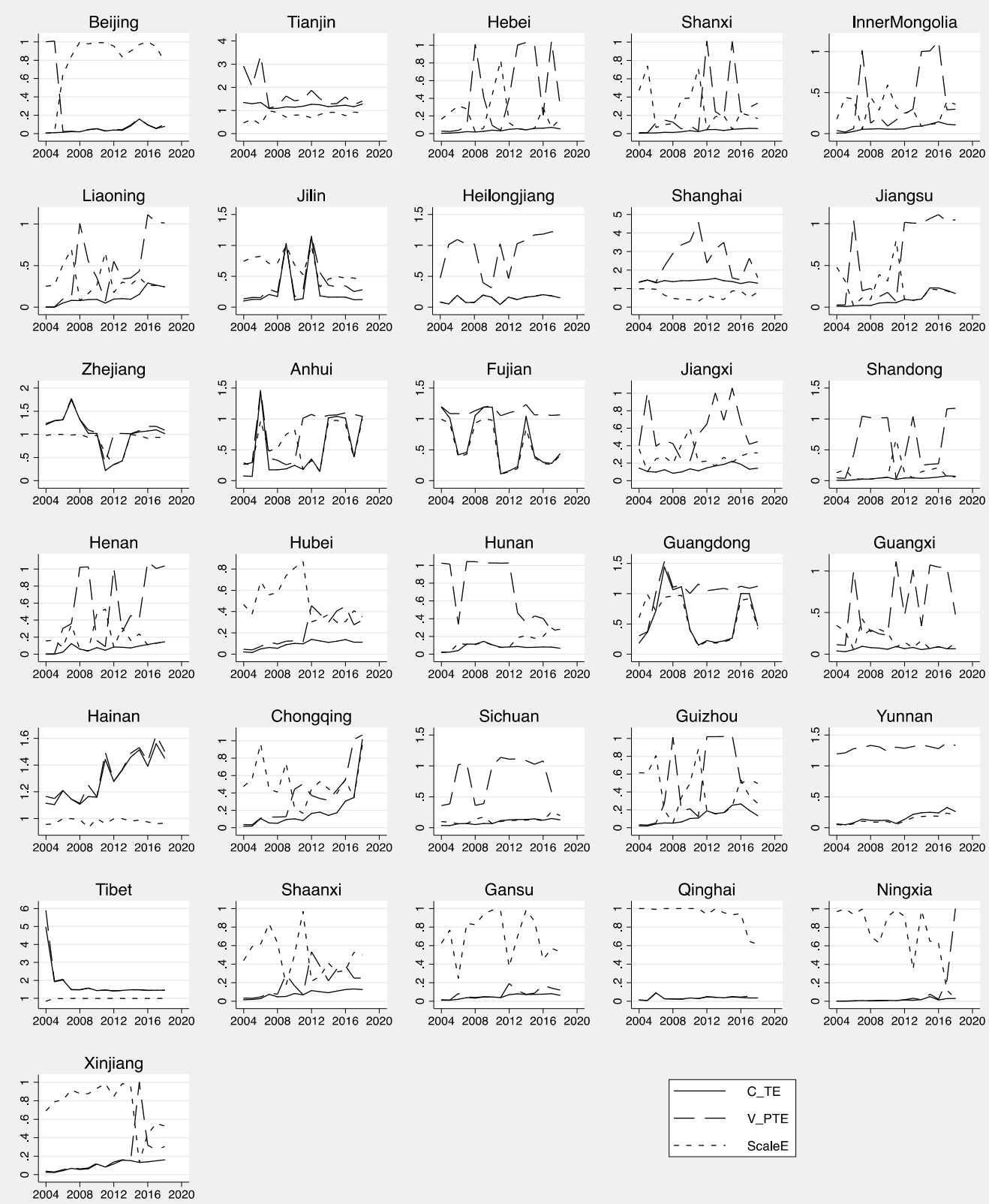

Figure 2: Line chart of China's forestry investment efficiency from 2004 to 2018 
At the same time, we have also noticed that in Hebei, Shanxi, Inner Mongolia, Liaoning, Jiangsu, Jiangxi, Henan, Guizhou, and Shaanxi provinces, pure technical efficiency does not match scale efficiency. Because pure technical efficiency and scale efficiency always show the opposite direction of change, the comprehensive forestry investment efficiency of these provinces has shown a lower level. This shows that forestry investment and production activities in these provinces are not stable, the industrial structure is not mature enough, and the economy is underdeveloped. Therefore, it cannot provide an effective environment for forestry production activities.

The output variables we selected not only reflect economic benefits but also cover environmental benefits. Therefore, when evaluating the effect of forestry investment, the results of the model also reflect the effect of improving the environment. Combining the analysis of forestry investment intensity in Figure 1 and the forestry investment efficiency value calculated in this section, we find that provinces with high forestry investment intensity do not necessarily have good investment effects. For example, provinces such as Guangxi and Sichuan have more reasonable resource allocation, but their economies of scale are low. Even if the investment is very sufficient but cannot match the development needs, the effect of forestry investment is still not satisfactory. However, the amount of forestry investment in some developed provinces is relatively low. However, their investment has reached the best results at the forefront of production, such as Shanghai and Tianjin. This result shows that although their input elements are very limited, if the input-output structure is reasonable and the state of scale effect is reached, the greatest forestry investment benefits can be obtained.

\subsection{Slack variable results of Super-SBM model}

As the efficiency of comprehensive forestry investment in China's provinces is generally low, we will further analyze the specific reasons for the unreasonable efficiency of comprehensive forestry investment in various provinces. One of the main reasons for choosing the Super-SBM model is that it considers slack variables. The value of the slack variable reflects the irrationality of input and output and the direction of improvement to a certain extent. Fig. 3 and Fig. 4 show the analysis results of the slack variable values of input variables and output variables in the comprehensive forestry investment efficiency of various provinces in China.

Through the slack variables shown in Fig. 3, among them, the value of the slack variable greater than 0 represents the distance between the DMU and the optimal input or output. Therefore, we can analyze the redundancy of forestry investment in various provinces in China. We can clearly see that Hebei, Shanxi, Inner Mongolia, Liaoning, Anhui, Fujian, Jiangxi, Shandong, Hubei, Guangdong, Guangxi, Chongqing, Sichuan, Yunnan, Shaanxi, Gansu, Ningxia and Xinjiang have a certain overinvestment in forestry areas. However, forestry practitioners in Beijing, Jilin, Heilongjiang and Jiangsu provinces have overinvestment. In 
addition, forestry investment in Beijing, Jiangsu, Shandong, and Guangxi has overinvestment.
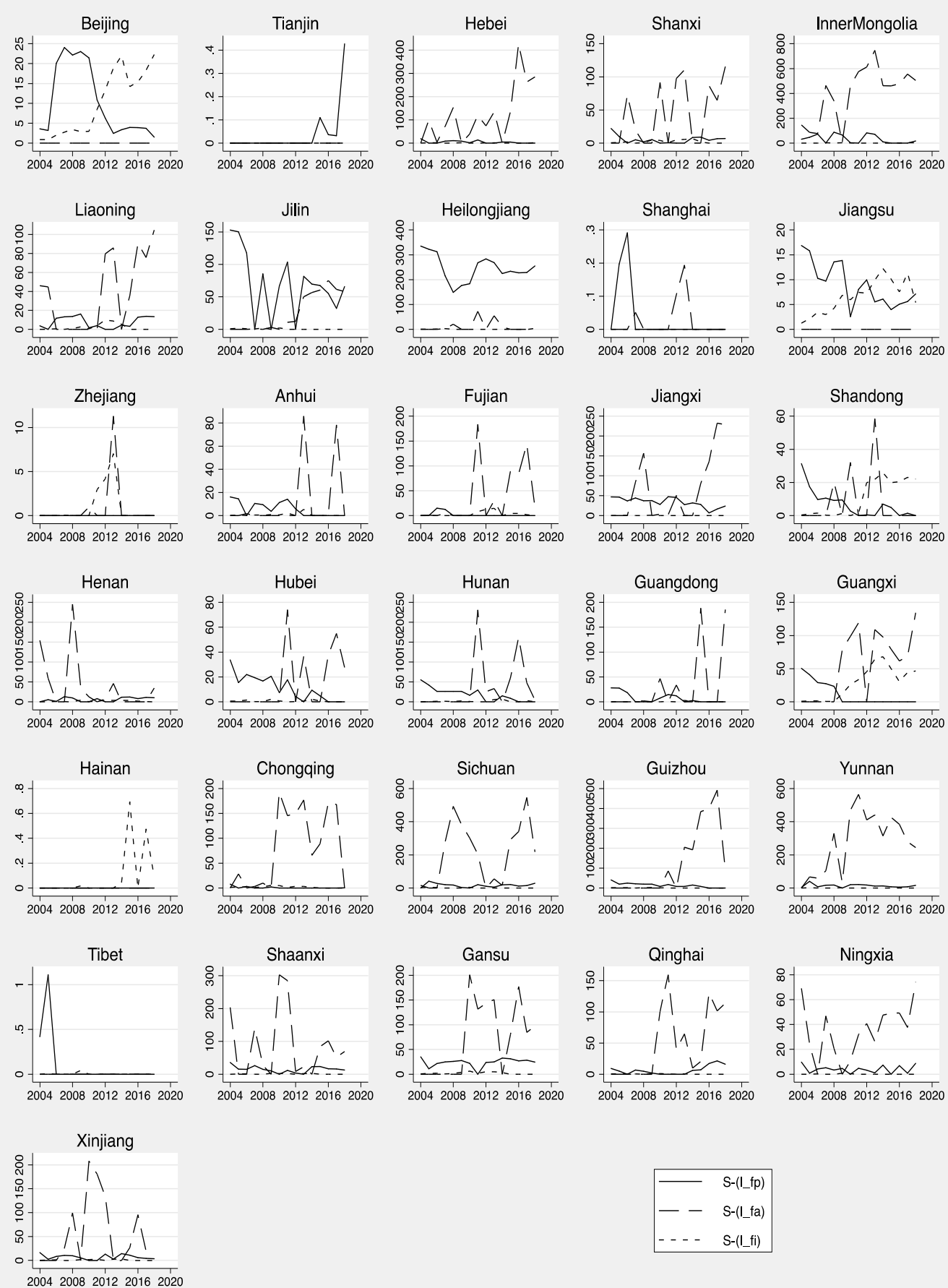

Figure 3: Slack values of input variables in China's provinces from 2004 to 2018 

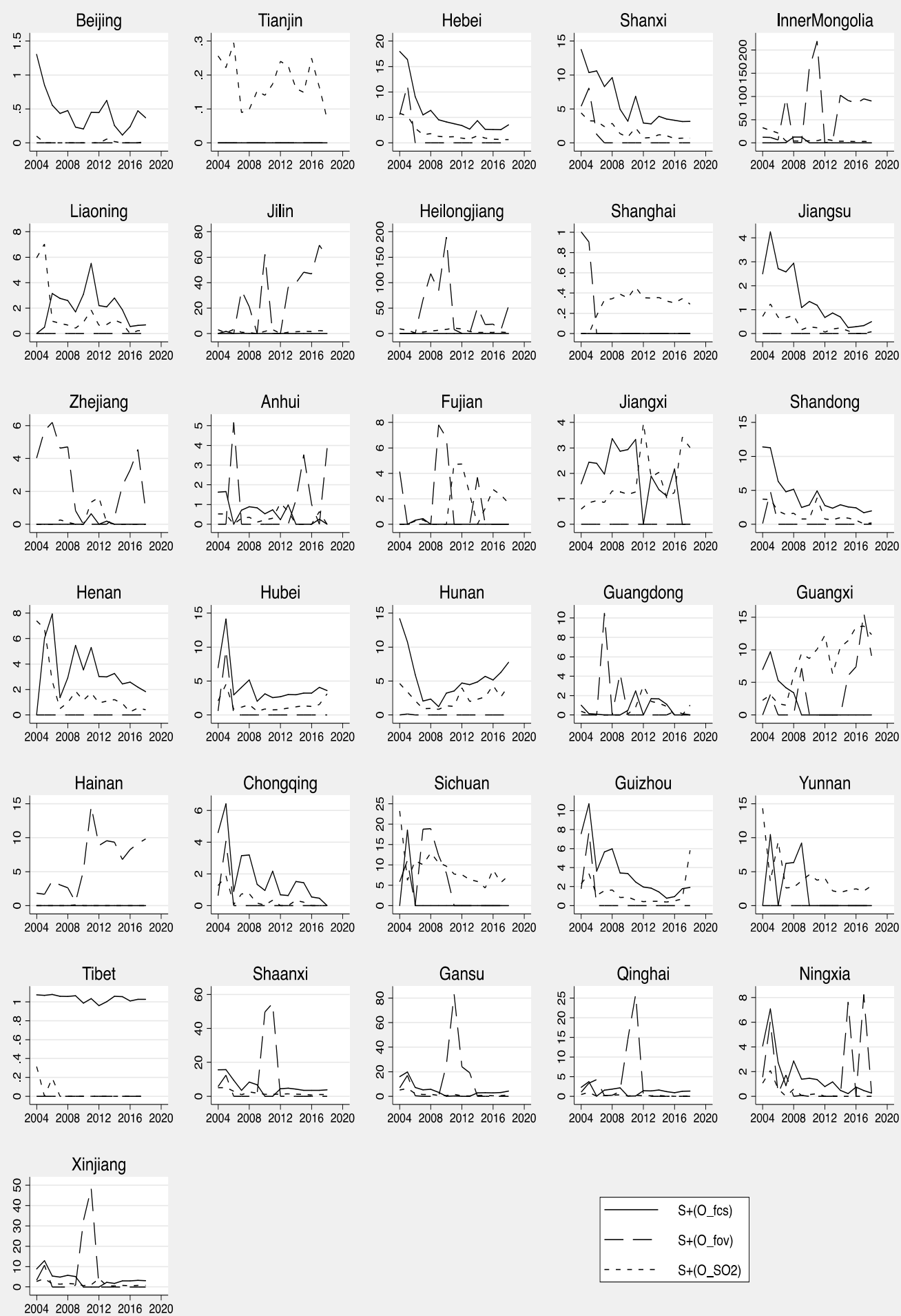

\section{Figure 4: Slack values of output variables in China's provinces from 2004 to 2018}


From this, we find that the reasons for the low efficiency of forestry investment in various provinces in China are different. For most provinces, their forestry practitioners and funds are insufficient, resulting in the inability to make full use of forestry land. In contrast, Beijing's forestry investment and forestry practitioners clearly surplus, which confirms previous speculations about the "low efficiency" of Beijing's forestry investment. Beijing's land resources are very limited, and blindly increasing forestry funds and employees cannot effectively improve economic and environmental benefits. Jiangsu is also facing a similar situation to Beijing. Shandong and Guangxi also have surpluses in forestry investment, but their forestry land resources are relatively sufficient. Their "inefficiency" is different from that of Beijing. This may be because they lack labor to make full use of these resources and limit their ability to utilize and absorb investment.

From Fig. 4, we can see the forestry output of each province in China. Among them, Beijing, Hebei, Shanxi, Liaoning, Jiangsu, Jiangxi, Shandong, Henan, Hubei, Hunan, Chongqing, Guizhou and Tibet have relatively insufficient forest carbon sinks. The forestry output values of Inner Mongolia, Jilin and Hainan are insufficient. The air purification capacity of forests in Tianjin, Shanghai, Jiangxi, Guangxi and Yunnan is relatively weak.

We found that the forest carbon sinks are insufficient in forestry investment output in most provinces, and there may be two reasons for this. One is that in forestry investment projects, cultivated tree species have weak carbon sequestration capacity. The other is that if the rotation cycle of the planted trees is too short or too long, the trees will be immature or have been aging, and they will not be able to fully exert their carbon sequestration capacity. This will not only reduce the absorption of carbon dioxide and sulfur dioxide but also occupy land resources and affect production.

\subsection{Results of the DEA-Malmquist model}

Table 3 shows the overall results of the decomposition of China's forestry investment efficiency using the DEA-Malmquist model. The DEA-Malmquist model helps us understand the changes in China's forestry investment efficiency from a dynamic perspective. In Table 3, ML-effch represents the TEC, ML-techch represents the TP, ML-pech represents the PTE, ML-sech represents the SE, and ML-tfpch represents the Malmquist index of the total factor productivity of forestry investment. Their value greater than 1 indicates a certain improvement relative to the efficiency value of the previous year, equal to 1 indicates no change in the efficiency value relative to the previous year, and less than 1 indicates a decrease in the efficiency value relative to the previous year. TEC represents whether the DMU's forestry investment management methods and decision-making have been improved. PTE represents whether the DMU's ability to obtain maximum output under a given input situation has been improved. SE represents the change in the distance between DMU and the optimal forestry 
investment scale. TP represents whether the DMU's forestry investment application technology has improved. The Malmquist index represents whether the DMU's forestry investment efficiency has improved.

From Table 3, we find that China's forestry investment efficiency did not fluctuate much from 2004 to 2018, and the Malmquist index of China's forestry investment was between 0.72 and 1.18. The Malmquist index was less than 1 in 2004-2006, indicating that China's forestry investment efficiency was declining at this stage. Through further analysis, we find that it is mainly caused by the lower TP, which implies that China's use of technology for forestry investment at this time is relatively low. During the 2006-2009 period, the Malmquist index was always greater than 1, indicating that China's forestry investment efficiency was gradually improving at this stage. Through further decomposition, we find that it is also mainly caused by the increase in TP, from 0.67 to 1.03 , then to 1.07 , and then to 1.17. Hereafter, the Malmquist index fluctuated approximately 1 from 2009 to 2018, and TP is still the main reason why the Malmquist index is lower than 1. In addition, when we decomposed TEC, we also noticed that SE was lower than 1 for most of the period, indicating that China's forestry investment was not carried out on an appropriate scale, and there was a waste of capital.

Table 3: Changes in China's overall forestry investment efficiency

\begin{tabular}{|c|c|c|c|c|c|}
\hline year & ML-effch & ML-techch & ML-pech & ML-sech & ML-tfpch \\
\hline $2004-2005$ & 0.95 & 0.95 & 0.98 & 0.97 & 0.90 \\
\hline $2005-2006$ & 1.06 & 0.67 & 1.16 & 0.92 & 0.72 \\
\hline $2006-2007$ & 1.02 & 1.03 & 1.03 & 0.99 & 1.04 \\
\hline $2007-2008$ & 1.04 & 1.07 & 1.01 & 1.03 & 1.12 \\
\hline $2008-2009$ & 1.01 & 1.17 & 1.01 & 0.99 & 1.18 \\
\hline $2009-2010$ & 1.01 & 0.98 & 0.97 & 1.04 & 0.99 \\
\hline $2010-2011$ & 0.97 & 1.21 & 0.84 & 1.16 & 1.18 \\
\hline $2011-2012$ & 1.04 & 0.86 & 1.21 & 0.85 & 0.89 \\
\hline $2012-2013$ & 1.05 & 0.99 & 1.02 & 1.03 & 1.04 \\
\hline $2013-2014$ & 0.99 & 0.97 & 1.00 & 0.99 & 0.96 \\
\hline $2014-2015$ & 1.06 & 1.03 & 1.00 & 1.05 & 1.09 \\
\hline $2015-2016$ & 0.92 & 0.89 & 0.89 & 1.04 & 0.82 \\
\hline $2016-2017$ & 1.03 & 1.11 & 1.06 & 0.97 & 1.14 \\
\hline $2017-2018$ & 0.91 & 1.01 & 0.97 & 0.93 & 0.92 \\
\hline
\end{tabular}

Fig. 5 shows the specific situation of the Malmquist index of forestry investment efficiency in various provinces in China. From Fig. 5, we find that the Malmquist index of approximately half of China's provinces is greater than 1 in most periods. This shows that the efficiency of forestry investment in most provinces in China is gradually improving, which is consistent with the static analysis results of 
super-SBM. In addition, we noticed that the Malmquist index of Inner Mongolia, Liaoning, Heilongjiang, Shanghai, Shandong, Henan, and Shaanxi was less than 1 in many periods. This shows that the efficiency of forestry investment in these provinces has declined, and these provinces deserve more attention from the Chinese government. In addition, we found that TP is the main factor affecting the Malmquist index through the decomposition of the Malmquist index of various provinces in China, which is consistent with the previous analysis results. In the process of decomposing TEC in various provinces in China, we also found that most provinces did not invest in forestry at the appropriate scale of investment.
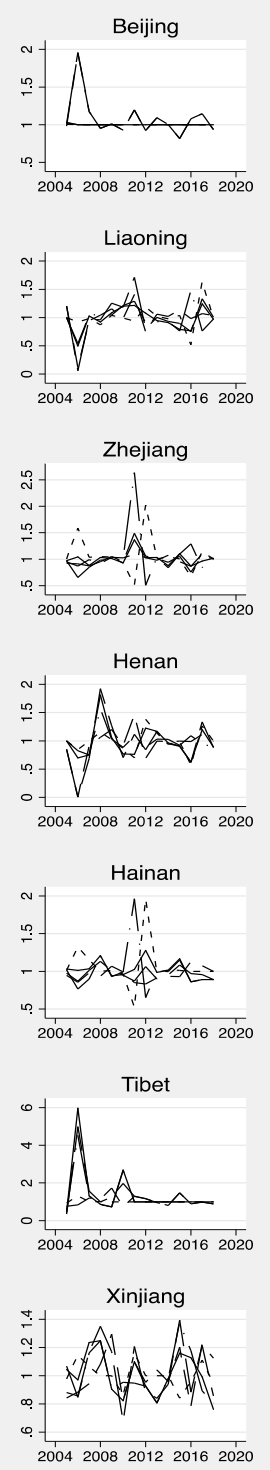
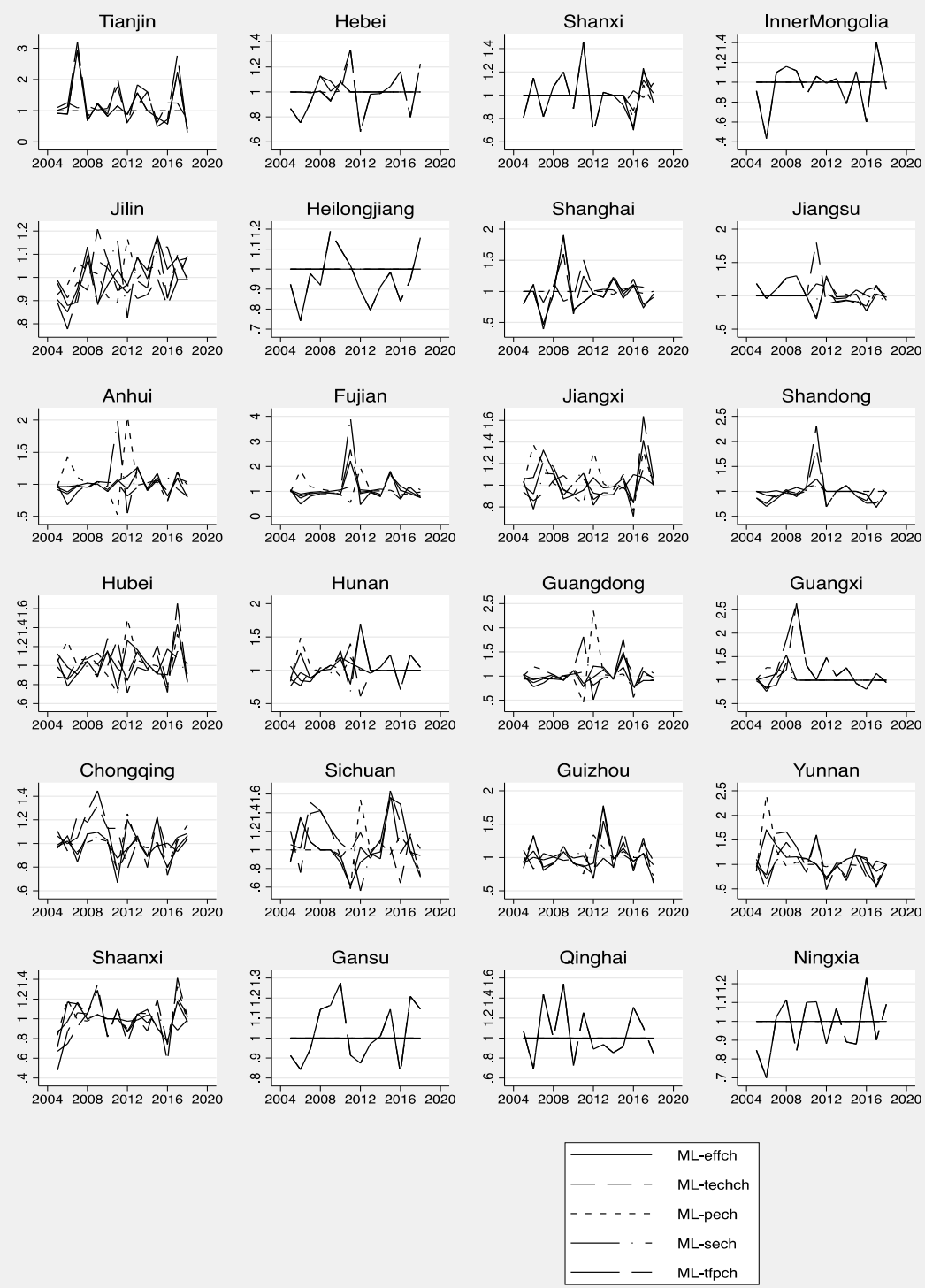

Figure 5: Changes in China's forestry investment efficiency from 2005 to 2018 


\section{Conclusions}

The sustainable and effective development of the forestry industry requires the rational allocation of resources when into production; on the other hand, it requires that both the economy and the atmospheric environment can benefit from it to maximize the efficiency of forestry investment. This paper uses the Super-SBM model and the DEA-Malmquist model to study the forestry investment efficiency of 31 provinces and cities in China from 2004 to 2017 from both static and dynamic aspects. Our conclusions are as follows:

(1) The comprehensive efficiency of forestry investment in most cities in China is low, including in some economically developed cities. After decomposing the comprehensive efficiency into pure technical efficiency and scale efficiency, it is found that the pure technical efficiency of forestry investment in most provinces is effective, while the scale efficiency is low, which reflects that the input-output structure of most provinces is reasonable, but the output rate of investment is low. There are also a few provinces, such as Beijing, which are economically developed, but the comprehensive efficiency of forestry investment is not high. These provinces are mainly limited by the resources invested, which affects the effect of forestry investment.

(2) In view of the inefficient provinces of forestry investment, we analyzed the slack of their inputs and outputs and found that the forestry investment in the economically developed provinces was obviously redundant, while almost all the inefficient provinces were deficient in forest carbon sink output. This result indicates that the economic benefits of China's overall forestry investment were basically qualified, but there were still obvious deficiencies in the environmental benefits. The ability of planted trees to improve the atmospheric environment is limited.

(3) The Malmquist index of China's forestry investment efficiency shows that forestry investment efficiency in most provinces has improved in recent years. Through the decomposition of the Malmquist index, we find that the key to the growth of China's forestry investment efficiency is the rate of technological progress. This shows that China's application technology for forestry investment has not improved in recent years. In addition, the results also show a certain degree of decline in scale efficiency, which means that the low rate of forestry investment and output is deepening.

According to the empirical results of this paper, we have some suggestions for investors. First, the efficiency of forestry investment has certain requirements for resource allocation, and investors must rationally determine the amount of forestry investment according to the current situation of the resource endowment supply in different regions. Second, the experimental results show that the greatest problem in forestry investment is the low environmental benefits because the carbon sequestration capacity of the forest is weak. Therefore, before investment, investors should consult with relevant forest planting experts to select trees with a strong carbon sequestration capacity for cultivation. They should scientifically 
manage the rotation period of the forest to achieve the optimal sum of economic and environmental output of the forest. Third, to improve the application technology of forestry investment, computer technology can be introduced to build a forestry investment system and real-time adjustment of inputs in different regions to obtain maximum output.

ACKNOWLEDGEMENTS. The authors are grateful to those who improved this article. We would also like to thank the editors and reviewers for their insightful comments on this research. The authors are grateful to the National Natural Science Foundation of China (71473010).

\section{References}

[1] Alix-Garcia, J.M., Sims, K.R.E. and Yañez-Pagans, P. (2015). Only one tree from each seed? Environmental effectiveness and poverty alleviation in Mexico's payments for ecosystem services program. American Economic Journal: Economic Policy, 7(4), pp. 1-40.

[2] Allevi, E., Basso, A., Bonenti, F., Oggioni, G. and Riccardi R. (2019). Measuring the environmental performance of green SRI funds: A DEA approach. Energy Economics, 79(C), pp. 32-44.

[3] Bostian, M., Färe, R., Grosskopf, S. and Lundgren T. (2016). Environmental investment and firm performance: A network approach. Energy Economics, 57, pp. 243-255.

[4] Baniya, B., Giurco, D. and Kelly, S. (2021). Green growth in Nepal and Bangladesh: Empirical analysis and future prospects. Energy Policy, 149, pp. 112049.

[5] Banacloche, S., Cadarso, M.A., Monsalve, F. and Lechon, Y. (2020). Assessment of the sustainability of Mexico green investments in the road to Paris. Energy Policy, 141, pp. 111458.

[6] Chhabra, A. (2002). Growing stock-based forest biomass estimate for India. Biomass and Bioenergy, 22(3), pp. 187-194.

[7] Cai, X., Lu, Y., Wu, M. and Yu, L. (2018). Does environmental regulation drive away inbound foreign direct investment? Evidence from a quasi-natural experiment in China. Journal of Development Economics, 123, pp. 73-85.

[8] Caves, D.W., Christensen, L.R. and Diewert W.E. (1982). The Economic Theory of Index Numbers and the Measurement of Input, Output, and Productivity. The Econometric Society, 50(6), pp. 1391-1414.

[9] Chen, C., Park, T., Wang, X., Piao, S., Xu, B., Chaturvedi, R.K., Fuchs, R., Brovkin, V., Ciais, P., Fensholt, R., Tømmervik, H., Bala, G., Zhu, Z., Nemani, R. R. and Myneni, R.B. (2019). China and India lead in greening of the world through land-use management. Nature Sustainability, 2, pp. 122-129. 
[10] Deng, L., Liu, G.B. and Shangguan Z.P. (2014). Land-use conversion and changing soil carbon stocks in China's 'grain-for-green' program: A synthesis. Global Change Biology, 20(11), pp. 3544-3556.

[11] Dmuchowski, P., Dmuchowski, W., Baczewska-Dmuchowski, A.H. and Gworek B. (2021). Green economy - growth and maintenance of the conditions of green growth at the level of polish local authorities. Journal of Cleaner Production, 301(10), pp. 126975.

[12] Fang, J., Guo, Z., Piao, S. and Chen, A. (2007). Terrestrial vegetation carbon sinks in China, 1981-2000. Science in China Series D: Earth Sciences, 50(9), pp. 1341-1350.

[13] Fang, J., Guo, Z., Hu, H., Kato, T., Muraoka, H. and Son, Y. (2014). Forest biomass carbon sinks in East Asia, with special reference to the relative contributions of forest expansion and forest growth. Global Chang Biology, 20, pp. 2019-2030.

[14] Färe, R., Grosskopf, S., Norris, M. and Zhang, Z. (1994). Productivity Growth, Technical Progress and Efficiency Change in Industrialized Countries. American Economic Association, 84(1), pp. 66-83.

[15] Griscom, B.W., Adams, J., Ellis, P.W., Houghton, R.A., Lomax, G., Miteva, D.A., Schlesinger, W.H., Shoch, D., Siikamäki, J.V., Smith, P., Woodbury, P., Zganjar, C., Blackman, A., Campari, J., Conant, R.T., Delgado, C., Elias, P., Gopalakrishna, T., Hamsik, M.R., Herrero, M., Kiesecker, J., Landis, E., Laestadius, L., Leavitt, S.M., Minnemeyer, S., Polasky, S., Potapov, P., Putz, F.E., Sanderman, J., Silvius, M., Wollenberg, E. and Fargione, J. (2017). Natural climate solutions. Proceedings of the National Academy of Sciences of the United States of America, 114, pp. 11645-11650.

[16] Jalkanen, A., Mäkipää, R., Ståhl, G., Lehtonen, A. and Petersson, H. (2005). Estimation of the biomass stock of trees in Sweden: Comparison of biomass equations and age-dependent biomass expansion factors. Annals of Forest Science, 62(8), pp. 845-851.

[17] Kangas, H.L., Lintunen, J., Pohjola, J., Hetemäki, L. and Uusivuori, J. (2011). Investments into forest biorefineries under different price and policy structures. Energy Economics, 33(6), pp. 1165-1176.

[18] Khovanskaia, M. and Ivanyi, Z. (2007). Possibilities and options for the clean development mechanism and the green investment scheme in central and eastern Europe: Macedonian and Romanian perspectives. Natural Resources Forum, 31(1), pp. 1-10.

[19] Li, L., Hao, T. and Chi, T. (2017). Evaluation on China's forestry resources efficiency based on big data. Journal of Cleaner Production, 142, pp. 513523.

[20] Lin, B. and Ge, J. (2019). Carbon sinks and output of China's forestry sector: An ecological economic development perspective. Science of The Total Environment, 655, pp. 1169-1180. 
[21] Lundgren, A.I., Milicevic, A., Uddin, G.S. and Kang, S.H. (2018). Connectedness network and dependence structure mechanism in green investments. Energy Economics, 72, pp. 145-153.

[22] Lin, B. and Ge, J. (2019). Valued forest carbon sinks: How much emissions abatement costs could be reduced in China. Journal of Cleaner Production, 224(1), pp. 455-464.

[23] Mell, I.C., Henneberry, J., Hehl-Lange, S. and Keskin, B. (2016). To green or not to green: Establishing the economic value of green infrastructure investments in the Wicker, Sheffield. Urban Forestry \& Urban Greening, 18, pp. 257-267.

[24] Moriarty, P. and Honnery, D. (2019). Ecosystem maintenance energy and the need for a green EROI. Energy Policy, 131, pp. 229-234.

[25] Malmquist, S. (1953). Index numbers and indifference surfaces. Trabajos de Estadistica, 4, pp. 209-242.

[26] Nery, T., Polyakov, M., Sadler, R. and White, B. (2019). Spatial patterns of boom and bust forestry investment development: A case study from Western Australia. Land Use Policy, 86, pp. 67-77.

[27] Ng, A. and Zheng, D. (2018). Let's agree to disagree! On payoffs and green tastes in green energy investments. Energy Economics, 69, pp. 155-169.

[28] Ottelin, J., Heinonen, J., and Junnila, S. (2018). Carbon and material footprints of a welfare state: Why and how governments should enhance green investments. Environmental Science and Policy, 86, pp. 1-10.

[29] Parsa, V.A., Salehi, E., Yavari, A.R. and Bodegom, P.M. (2019). Analyzing temporal changes in urban forest structure and the effect on air quality improvement. Sustainable Cities and Society, 48, pp. 101548.

[30] Qiu, Z., Feng, Z., Song, Y., Li, M. and Zhang, P. (2020). Carbon sequestration potential of forest vegetation in China from 2003 to 2050: Predicting forest vegetation growth based on climate and the environment. Journal of Cleaner Production, 252(10), pp. 119715.

[31] Rode, J., Pinzon, A., Stabile, M.C.C., Pirker, J., Bauch, S., Iribarrem, A., Sammon, P., Llerena, C.A., Alves, L.M., Orihuela, C.E. and Wittmer, H. (2019). Why 'blended finance' could help transitions to sustainable landscapes: Lessons from the unlocking forest finance project. Ecosystem Services, 37, pp. 100917.

[32] Ray, S.C. and Desli, E. (1997). Productivity growth, technical progress, and efficiency change in industrialized countries: Comment. American Economic Association, 87(5), pp. 1033-1039.

[33] Somogyi, Z., Cienciala, E., Mäkipää, R., Muukkonen, P., Lehtonen, A. and Weiss, P. (2007). Indirect methods of large-scale forest biomass estimation. European Journal of Forest Research, 126(2), pp. 197-207.

[34] Sobrinho, V.G., Lagutov, V. and Baran, S. (2020). Green with savvy? Brazil's climate pledge to the Paris Agreement and its transition to the green economy. Energy and Climate Change, 1, pp. 100015. 
[35] Schulze, E.D., Wirth, C. and Heimann, M. (2000). Managing Forests after Kyoto. American Association for the Advancement of Science, 289(5), pp. 5487.

[36] Sohag, K., Chukavina, K. and Samargandi, N. (2021). Renewable energy and total factor productivity in OECD member countries. Journal of Clean Production, 296, pp. 126499.

[37] Tone, K. (2001). A slacks-based measure of efficiency in data envelopment analysis. European Journal of Operational Research, 130(3), pp. 498-509.

[38] Tone, K. (2002). A slacks-based measure of super-efficiency in data envelopment analysis. European Journal of Operational Research, 143(1), pp. $32-41$.

[39] Wang, X., Feng, Z. and Ouyang, Z. (2001). The impact of human disturbance on vegetative carbon storage in forest ecosystems in China. Forest Ecology and Management, 148(1-3), pp. 117-123.

[40] Winjum, J.K., Brown, S. and Schlamadinger, B. (1998). Forest harvests and wood products: Sources and sinks of atmospheric carbon dioxide. Forest Science, 44(2), pp. 272-284.

[41] Wen, J., Wang, H., Chen, F. and Yu R. (2018). Research on environmental efficiency and TFP of Beijing areas under the constraint of energy-saving and emission reduction. Ecological Indicators, 84, pp. 235-243.

[42] Wu, L. and Zhang, Z. (2020). Impact and threshold effect of Internet technology upgrade on forestry green total factor productivity: Evidence from China. Journal of Cleaner Production, 271, pp. 122657.

[43] Xiao, J., Li, G., Zhu, B., Xie, L., Hu, Y. and Huang J. (2021). Evaluating the impact of carbon emissions trading scheme on Chinese firms' total factor productivity. Journal of Cleaner Production, 306, pp. 127104.

[44] Zeng, S., Jiang, X., Su, B. and Nan, X. (2018). China's SO2 shadow prices and environmental technical efficiency at the province level. International Review of Economics and Finance, 57, pp. 86-102.

[45] Zhang, P., He, Y., Feng, Y., Torre, R.D.L., Jia, H., Tang, J. and Cubbage, F. (2019). An analysis of potential investment returns of planted forests in South China. New Forests, 50(6), pp. 943-968.

[46] Zhang, Y., Yuan, J., You, C., Cao, R., Tan, B., Li, H. and Yang, W. (2020). Contributions of National Key Forestry Ecology Projects to the forest vegetation carbon storage in China. Forest Ecology and Management, 462(15), pp. 117981. 